\title{
Molecular analysis of even-skipped mutants in Drosophila development
}

\author{
Manfred Frasch, Rahul Warrior, Jonathan Tugwood, and Michael Levine \\ Department of Biological Sciences, Fairchild Center, Columbia University, New York, New York 10027 USA
}

\begin{abstract}
The homeo box gene even-skipped (eve) plays a key role in the regulation of the Drosophila segmentation pattern. eve $e^{-}$embryos lack segment borders and show altered activities of several segmentation genes, including fushi tarazu (ftz), engrailed (en), and wingless (wg). Here, we present evidence that eve influences its own expression in a tissue-specific manner. Each of four different eve mutations disrupts the normal eve expression pattern, and null mutations cause a premature loss of eve products in ectodermal, but not mesodermal, tissues. Molecular characterization of eve mutations indicates that disruptions of the eve pattern are not due to alterations in the eve promoter but, instead, involve abnormal eve proteins. Two different eve mutations cause single amino acid substitutions within the homeo box, and we discuss the implications of these changes with regard to homeo box gene function. We also present evidence that $e v e^{+}$gene activity is not only required for the activation of the odd-numbered en stripes but also for the correct positioning of each $f t z$ stripe. We present a model for the loss of en expression in eve ${ }^{-}$embryos, based on the concentration-dependent regulation of the $f t z$ pattern by $e v e^{+}$products.
\end{abstract}

[Key Words: Autoregulation; even-skipped; regulatory interactions; segmentation]

Received July 1, 1988; revised version accepted October 11, 1988.

The subdivision of the Drosophila embryo into a repeating series of homologous segments involves a hierarchy of interactions among a set of $>20$ different regulatory genes (Nüsslein-Volhard and Wieschaus 1980). Many of these genes contain copies of the homeo boxcoding sequence (for review, see Akam 1987; Levine and Harding 1987), and it has been suggested that some of the interactions occur at the level of transcription and are mediated by sequence-specific DNA-binding activities (Desplan et al. 1985; Hoey and Levine 1988). Regulatory interactions among three of these genes, evenskipped (eve) (Nüsslein-Volhard et al. 1985), fushi tarazu (ftz) (Wakimoto et al. 1984), and engrailed (en) (Kornberg 1981), provide a well-characterized model for the analysis of a gene hierarchy during early development. Here, we provide additional information regarding this regulatory circuit by analyzing the patterns of eve, $f t z$, and en expression in an allelic series of eve mutants. We report the cloning and sequencing of several eve mutations in an attempt to obtain some insight into the molecular basis for the control that eve exerts over eve, ftz, and en expression during development.

The segment polarity gene en plays a key role in the segmentation process. $e^{+}$products come to be expressed in a series of 14 evenly spaced stripes in the middle body region of gastrulating wild-type embryos (Kornberg et al. 1985; Fjose et al. 1985; DiNardo et al. 1985). Each segment primordium is composed of a strip of about four cells in width that encompasses the circumference of the embryo (Hartenstein et al. 1985). en is expressed in the posterior-most cell of each primordium, where it is required for the establishment and maintenance of the posterior compartment (Lawrence and Morata 1976; Kornberg 1981; DiNardo et al. 1985). en mutations cause the loss of segment borders and fusions between adjacent rows of denticle belts (Nüsslein-Volhard and Wieschaus 1980; Kornberg 1981).

Genetic circuitry studies suggest that one of the primary functions of eve and $f t z$ gene activity is to establish the 14-stripe en pattern during gastrulation /Carroll and Scott 1986; Harding et al. 1986; Howard and Ingham 1986; Macdonald et al. 1986). eve and $f t z$ are transiently expressed in a complementary series of seven stripes during early development (Carroll and Scott 1985; Hafen et al. 1984; Harding et al. 1986; Macdonald et al. 1986). $e v e$ is required for the activation of the odd-numbered en stripes (Harding et al. 1986; Macdonald et al. 1986), and $\mathrm{ftz}$ activity is needed for the even-numbered stripes (Howard and Ingham 1986). en proteins are detected within $10 \mathrm{~min}$ after the periodic $e v e$ and $f t z$ patterns are established during cellularization (DiNardo et al. 1985; Fjose et al. 1985; Kornberg et al. 1985), and eve and $f t z$ expression is repressed shortly thereafter (Hafen et al. 1984; Carroll and Scott 1985; Harding et al. 1986; Macdonald et al. 1986; Frasch et al. 1987). The anterior margin of each eve stripe coincides precisely with the odd-numbered en stripes, whereas the anterior margins of $f t z$ coincide with the even-numbered en stripes (Lawrence et al. 1987; see below). Recent DNA-binding studies are consistent with the notion that eve and $f t z$ serve as transcription factors in the activation of en expression. A full-length eve protein made in bacteria 
binds with high affinity to several sites within the en promoter (Hoey and Levine 1988). ftz- embryos lack the even-numbered en stripes and, consequently, possess only one-half the normal number of segment borders at advanced stages (Howard and Ingham 1986; DiNardo and O'Farrell 1987). The eve pattern is not altered in $\mathrm{ftz}^{-}$mutants (Harding et al. 1986), and the activation of the odd-numbered en stripes proceeds as in wild type (DiNardo and O'Farrell 1987). eve- embryos lack all middle body en stripes (Harding et al. 1986; Macdonald et al. 1986). As expected, the odd-numbered en stripes are not activated, resulting from the loss of the seven primary eve stripes that define the odd-numbered parasegments. What is more difficult to understand is why each of the even-numbered $e n$ stripes is also absent. Their absence is somewhat surprising because the $f t z$ pattern appears nearly normal in $e v e^{-}$embryos (Carroll and Scott 1986; Harding et al. 1986). Although a premature loss of $f t z^{+}$products has been observed in eve mutants, this does not obviously account for the failure to activate $e n$. Here, we attempt to determine why $f t z$ fails to activate the even-numbered en stripes in $e v e^{-}$embryos.

Another issue regarding interactions among eve, $f t z$, and en concerns the question of autoregulation. Autofeedback mechanisms have been proposed to be important for the definition of discrete patterns of gene expression in response to more crudely localized positional cues (e.g., Meinhardt 1986). Thus far, autoregulation does not appear to be emerging as a general rule underlying segmentation gene expression (e.g., see Redemann et al. 1988), and only a few instances have been clearly documented (Hiromi and Gehring 1987; Bienz and Tremml 1988). The most compelling case of an autoregulatory interaction has been obtained for $f t z$ (Hiromi and Gehring 1987). Recent studies have identified a distal region of the $\mathrm{ftz}$ promoter that is required for the maintenance of high levels of $f t z$ products during gastrulation and germ band elongation (Hiromi et al. 1985). It is not clear whether such autoregulation plays a role in the sharpening of the $f t z$ pattern from broad domains of expression to individual stripes. There is currently no direct evidence that either $e v e$ or en autoregulates its own expression. The demonstration that the eve protein binds with high affinity to several sites within the eve promoter provides circumstantial evidence that eve might influence its own expression (Hoey and Levine 19881.

Here, we examine the patterns of eve, ftz, and en expression in an allelic series of eve mutants. Each of the four mutants that was examined alters the eve pattern, suggesting that eve might influence its own expression. Several of the eve mutations map within the proteincoding sequence, suggesting that the abnormal eve patterns do not result from disruptions of the promoter but, instead, involve a breakdown in a trans-regulatory interaction. The altered eve patterns that are observed suggest that this autoregulatory interaction might not only be important for high level eve expression but also for determining its limits of expression. Two of the muta- tions map within the homeo box and provide further insights regarding the way in which homeo box proteins might control gene expression. Finally, we present evidence that the correct positioning of $f t z$ stripes depends on $e v e^{+}$gene activity. In weak eve mutants, the $f t z$ pattern is shifted to slightly more anterior positions, resulting in pairwise alignments of adjacent $e n$ stripes. In more severe eve mutations, $f t z$ products are shifted into regions of the embryo where they are unable to participate in the activation of $e n$. We propose that quantitative differences in the levels of the eve protein present within each eve expression stripe are functionally important in this regulation of the ftz pattern.

\section{Results}

Wild-type patterns of eve, $\mathrm{ftz}$, and en expression

As has been shown previously, the patterns of eve and $f t z$ expression are nearly complementary in cellular blastoderm-stage wild-type embryos (Fig. 1A), and the patterns are precisely reciprocal by the beginning of gastrulation (Fig. 1B) (Frasch and Levine 1987). Both genes are expressed in a series of seven transverse stripes along the anterior-posterior axis; in Figure 1, each eve stripe is stained green, whereas each $f t z$ stripe is red. Note that during early stages (Fig. 1A), the anterior margin of each $\mathrm{ftz}$ stripe slightly overlaps with the posterior border of each eve stripe. The double-staining pattern gives the appearance of a double-segment unit, with adjacent units separated by a gap of one cell that expresses only a very low level of eve. By the beginning of gastrulation, the anterior margin of each $f t z$ stripe has sharpened, which appears to result from the very rapid loss of both $e v e$ and $f t z$ products in the cell where eve and ftz overlapped during earlier stages (cf. Fig. 1A,B). At this time, the anterior margins of adjacent $e v e$ and $f t z$ stripes are evenly spaced.

The localization of en protein within a series of 14 evenly spaced stripes is first observed just after the eve and $f t z$ patterns have sharpened and are complementary. At this time, the anterior margin of each eve stripe coincides almost exactly with the odd-numbered en stripes (Fig. 1C). Transiently, one or two cells at the anterior margin of an eve stripe are observed to stain with the eve antibody, but not with the en antibody (see arrows, Fig. 1C). By the onset of germ band elongation, the anterior margin of each eve stripe is precisely coincident with each of the odd-numbered en stripes (Fig. 1D-F; the arrows highlight the relationship between the second eve stripe and the third en stripe). A similar correlation between the $f t z$ pattern and the even-numbered en stripes is also observed (data not shown; see Lawrence et al. 1987). The relationship between the wild-type eve, $f t z$, and en patterns is summarized in Figure 8.

\section{Molecular cloning of mutant eve alleles}

The patterns of $e v e, f t z$, and $e n$ expression were analyzed in four different eve mutants: $(1)$ eve $e^{I R 559} ;(2)$ eve $e^{3.77 .17} ;(3)$ $e v e^{I D 19}$; and (4) $e v e^{R 13}$ (Nüsslein-Volhard et al. 1985). Here, we show that IIR59 and ID19 map within the eve 
Frasch et al.
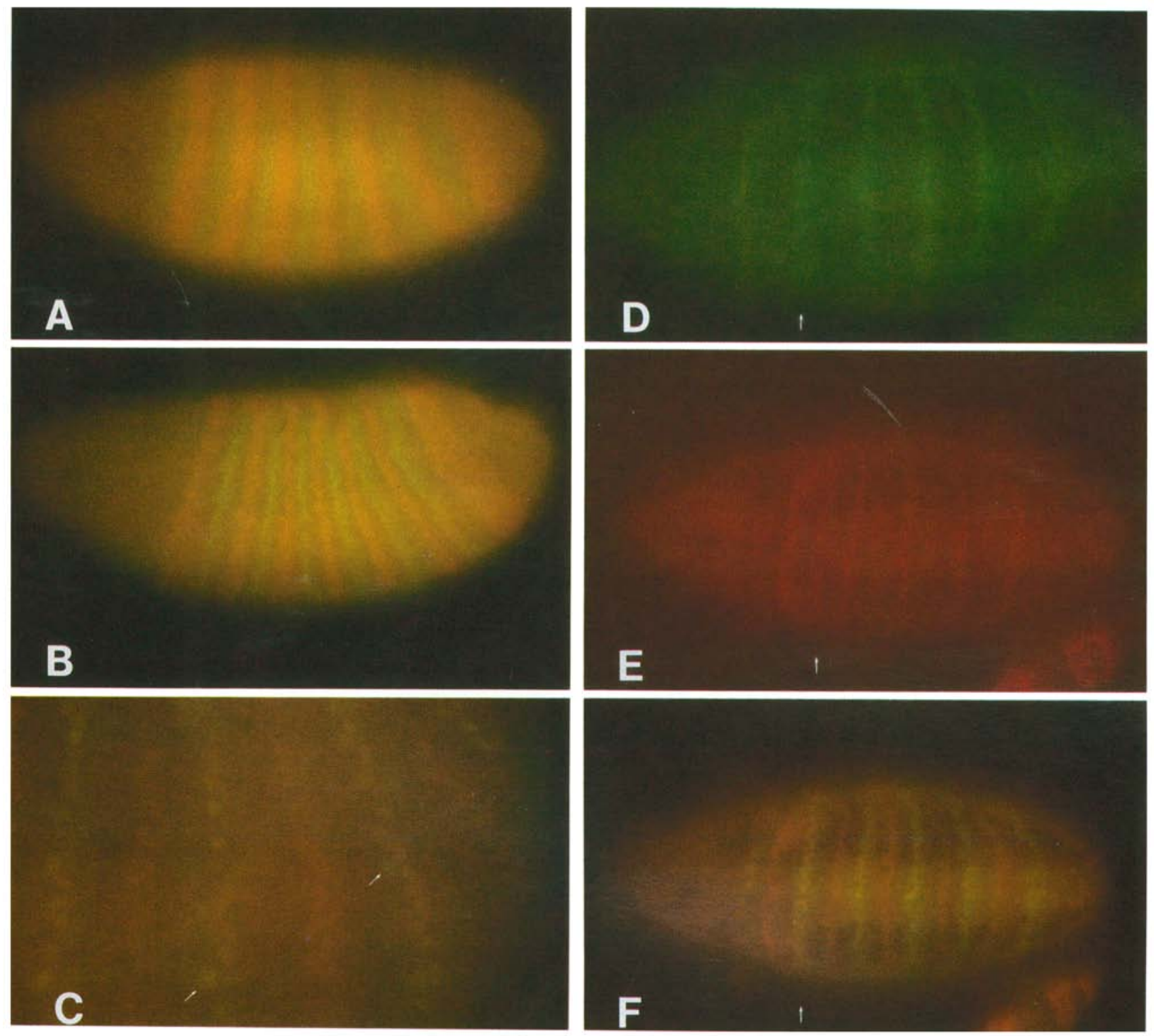

Figure 1. Wild-type patterns of $e v e, f t z$, and en expression. Whole-mount preparations of fixed embryos were stained with rabbit anti-eve antibodies, a mouse anti-ftz serum, and a monoclonal anti-en antibody. Indirect immunofluorescence was done with an FITC-conjugated secondary antibody for detecting eve (green), and a TRITC-conjugated secondary antibody for $f t z$ and $e n$ (red). ( $A, B$, $C, F)$ Photographs are double exposures that show both the FITC and TRITC signals. Embryos are oriented with the anterior end to the left. (A) Cellular blastoderm embryo double-stained with anti-eve and anti-ftz antibodies. Note that there is slight overlap between the posterior regions of the $e v e$ stripes and the anterior regions of the $f t z$ stripes. These nuclei appear yellow. $(B)$ eve (green) and $f t z(\mathrm{red})$ staining of a gastrulating embryo. By this time, the patterns are complementary, and a one-cell gap separates adjacent $e v e$ and $f t z$ stripes. $(C)$ High-magnification view of an embryo at the onset of germ band elongation that was double-stained with eve (green) and en (red). Note that the odd-numbered en stripes coincide quite closely with the eve stripes (region of overlap stains yellow). A few nuclei (green) express eve but little or no en (arrows). (D) Embryo undergoing germ band elongation stained with anti-eve antibody. The eve stripes are two to three cells in width and are separated by gaps of five to six cells. (E) en expression in the same embryo shown in $D$. The en stripes are evenly spaced. Note that the odd-numbered stripes (arrow shows stripe 3 ) are of weaker intensity in posterior regions of the embryo. $(F)$ Double exposure of the eve and en signals shown in $D$ and $E$. The odd-numbered en stripes coincide with the anterior margins of the eve stripes (e.g., the arrow indicates yellow-colored nuclei of eve stripe 2 plus en stripe 3 ). 
protein-coding sequence, as summarized in Figure 2.

The R13 mutation is a null allele, and homozygotes show the 'denticle lawn' phenotype, whereby all segment borders are absent in the middle body region. Consistent with this null phenotype is the finding that the eve protein is not detected in R13/R13 homozygotes (Frasch et al. 1987). However, as shown below, the R13 allele does encode an eve RNA that can be detected by in situ hybridization. These observations suggest that R13 is a nonsense mutation, which either fails to encode a protein, or encodes an unstable peptide.

Only two other eve null alleles have been identified. One of these, called 1.27, is a small deletion that removes the entire eve transcription unit. The second is a temperature-sensitive allele, called ID19 (Nüsslein-Volhard et al. 1985). At the restrictive temperature of $31^{\circ} \mathrm{C}$, ID19 homozygotes display the denticle lawn phenotype, which is virtually identical to that observed for R13 homozygotes. At lower temperatures, progressively less severe phenotypes are observed. For example, at $25^{\circ} \mathrm{C}$ ID 19 homozygotes show a pair-rule phenotype, whereby the even-numbered segments (or odd-numbered parasegments| are absent. At more permissive temperatures, such as $14^{\circ} \mathrm{C}$ or $18^{\circ} \mathrm{C}$, an essentially normal segmentation pattern is observed. Only one significant nucleotide substitution was identified within the ID19 sequence, which changes a CGC codon to a CAC codon at amino acid residue 121 (see Experimental procedures). This substitutes an arginine residue for a histidine residue within a highly conserved region of the eve homeo box, near the putative DNA-binding helix (Laughon and Scott 1984).

The 3.77 .17 allele is a hypomorph that does not abolish $e v e^{+}$gene function; homozygotes show a pairrule phenotype similar to that observed for ID19/ID19 embryos grown at $25^{\circ} \mathrm{C}$ (Nüsslein-Volhard et al. 1985). The 3.77.17 allele has been shown to contain a small deletion in the $3^{\prime}$ half of the $e v e$-coding sequence (Hoey et al. 1988). This deletion causes a frameshift that replaces the carboxy-terminal 134 amino acid residues of the native protein with 79 extraneous residues. The frameshift does not affect the homeo box, which is located within the amino-terminal half of the protein.

The IIR59 allele is a hypomorph, and homozygotes show a pair-rule phenotype that is somewhat less severe than that observed for 3.77.17 homozygotes or for ID19 mutants grown at $25^{\circ} \mathrm{C}$ (Nüsslein-Volhard et al. 1985). The IIR59 allele contains a single significant nucleotide substitution within the eve protein-coding sequence. This substitution converts a threonine residue to an isoleucine and maps within the amino-terminal portion of the eve homeo domain (see Fig. 2).

In summary, the molecular basis of the four known eve point (or pseudopoint) mutations corresponds quite closely to the level of genetic activity that each of these alleles displays in vivo. The R13 allele appears to be a protein null and shows no eve gene activity in vivo. The ID19 allele shows no activity at the restrictive temperature of $31^{\circ} \mathrm{C}$ and contains an amino acid substitution in a region of the eve homeo box that is likely to reduce strongly, or eliminate, the DNA-binding activity of the protein (see Discussion). The 3.77.17 mutation is a strong hypomorph and has been shown to lack the normal carboxy-terminal one-third of the native protein. And, finally, the most mild of the mutant eve alleles, IIR59, corresponds to a single amino acid substitution in a region of the homeo box that might not be directly involved in DNA binding.

\section{eve autoregulation}

The eve expression pattern is abnormal in each of the eve mutants examined. Each shows an abnormal spacing of the eve stripes during blastoderm stages, and the sharpening of the pattern is abnormal during gastrulation. There is a premature loss of expression in null $\mathrm{mu}-$ tants.

The eve pattern is only slightly altered in young IIR59 homozygotes (data not shown). However, during germ band elongation, each eve stripe appears somewhat

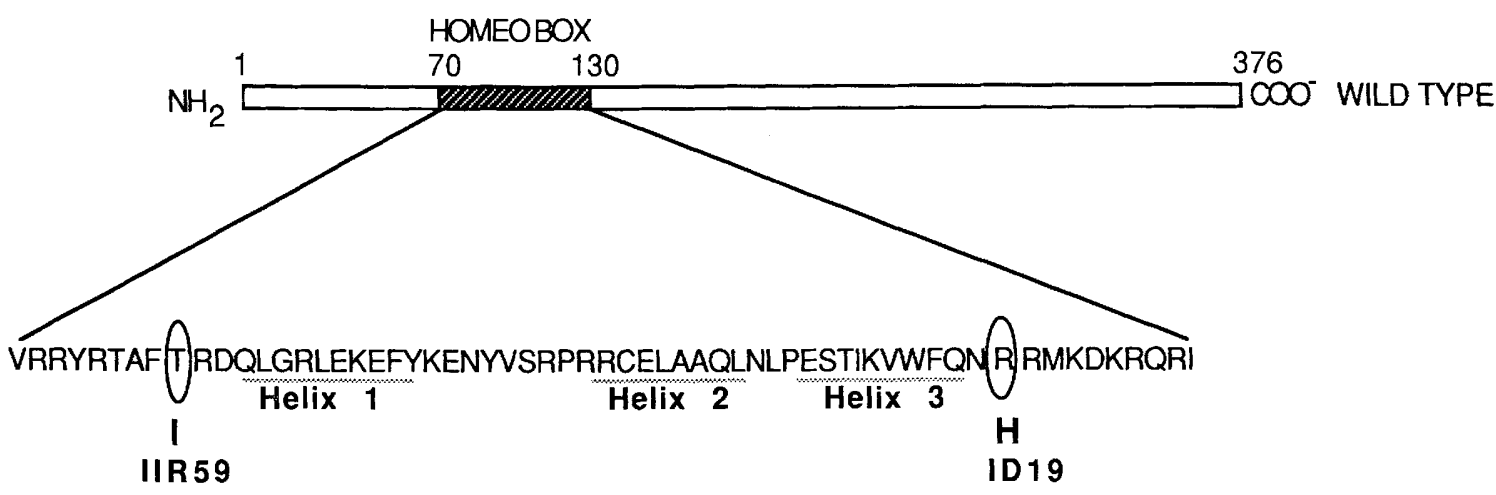

Figure 2. Summary of the ID19 and IIR59 mutations. The eve protein is composed of 376 amino acid residues, and the homeo box extends from residue 70 to 130 (hatched). The amino acid sequence of the homeo box is shown in the one-letter code. Chou and Fasman analysis predicts three $\alpha$-helices, labeled 1,2, and 3 . Helix 3 corresponds to the putative recognition helix that is thought to make direct contact with DNA. The IIR59 mutation changes the threonine residue at position 75 to an isoleucine. The ID19 mutation replaces the arginine residue at position 121 with a histidine. 
broader than normal (Fig. 3A; cf. with Fig. 1D). A more dramatic effect on the eve pattern is seen in 3.77 .17 homozygotes. The initial seven stripes are not evenly distributed along the length of pregastrulating embryos (Fig. 4A). In particular, there are partial pairwise fusions of stripes 1 and 2 and, to a lesser extent, stripes 3 and 4 . By the onset of germ band elongation, each stripe is abnormally broad (Fig. 4B). Instead of observing a gradual sharpening of the eve pattern due to the loss of expression in posterior cells, each stripe remains broad and nearly extends to the adjacent stripe. Moreover, these 'stripes' persist for longer periods of development, as compared with wild-type embryos. Normally, the eve stripes are lost by the completion of germ band elongation, and the only expression that is detected occurs within a ring of cells surrounding the proctodeum (Frasch et al. 1987). In wild-type embryos this ring of staining is detectable only after the loss of the seven original eve stripes, whereas 3.77 .17 mutants show a persistence of these stripes after the proctodeal ring has appeared (Fig. 4E).

Each of the broad eve stripes detected in $3.77 .17 \mathrm{mu}$ tants appears to contain a strong stripe and a closely juxtaposed weak stripe (Fig. 4E). Wild-type embryos at this stage show a total of 14 narrow stripes: the 7 original stripes and 7 weaker stripes that arise during gastrulation (Macdonald et al. 1986; Frasch et al. 1987). It is possible that each 'double stripe' seen in the mutant includes broader versions of one original strong stripe plus one weaker stripe. Note that the strong and weak components of each double stripe are not evenly spaced. It appears that each of the weaker stripes is shifted anteriorly, relative to the stronger original stripes in the mutant (see below).

The eve pattern was analyzed in ID19 homozygotes raised at the restrictive temperature of $31^{\circ} \mathrm{C}$, which produces the null denticle lawn phenotype (Nüsslein-Volhard et al. 1985). There are partial pairwise fusions of adjacent eve stripes during the establishment of the pattern, similar to that observed for 3.77 .17 mutants: stripes 1 and 2, 3 and 4, etc., are closer together and not evenly spaced as in wild type (Fig. 5A). Furthermore, not all of the stripes are uniformly intense. Stripes 1, 5, and 6 are weaker than the others. There is a premature loss of $e v e$ expression during gastrulation, with the ventral regions of each stripe decaying prior to the dorsal regions (Fig. 5B). The first eve stripe is the first to be lost, but all of the stripes disappear well before the time when they
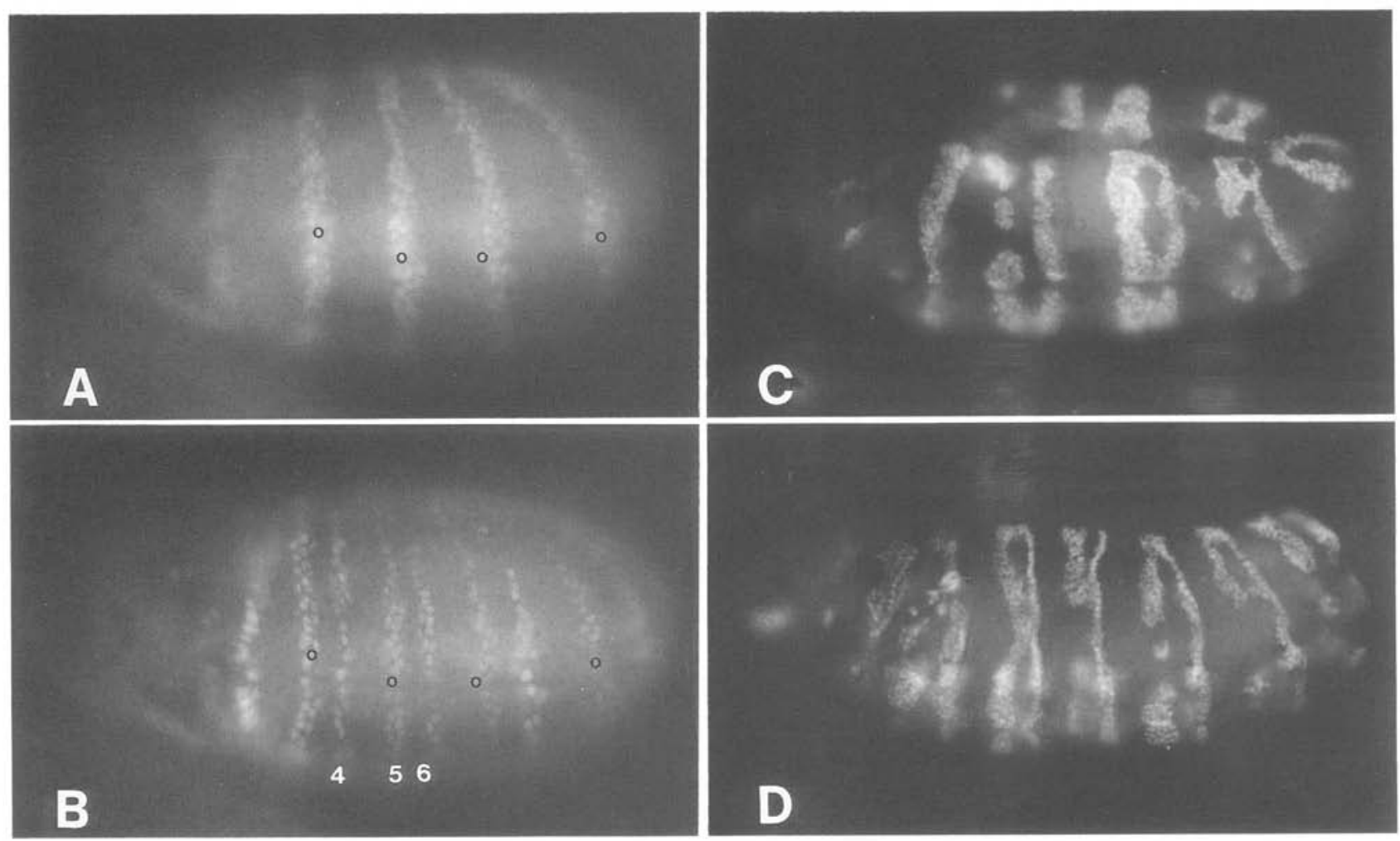

Figure 3. eve and en expression in eve hypomorphs. $(A, B)$ IIR59 homozygote at the onset of germ band elongation that was doublestained with anti-eve and anti-en antibodies; $(C, D) 3.77 .17$ homozygotes stained with anti-en. $(A)$ Photographed to show eve staining. Note that the stripes are slightly broader, as compared with those of wild-type embryos of the same age (see Fig. 1D). (B) Photographed to show en staining. The number of the en stripes is normal; however, the spacing is abnormal, and there are pairwise alignments of adjacent stripes. The circles show examples of cells that express both $e v e$ and en. $(C) 3.77 .17$ mutant after germ band elongation. By this time, pairs of en stripes have partially fused. Note that only a few of the cells within the first stripe are stained, and other odd-numbered stripes are incomplete (see DiNardo and O'Farrell 1987). (D) 3.77.17 mutant after germ band retraction. Only one-half the normal number of segmental furrows have formed, which occur just posterior to the even-numbered en stripes. 

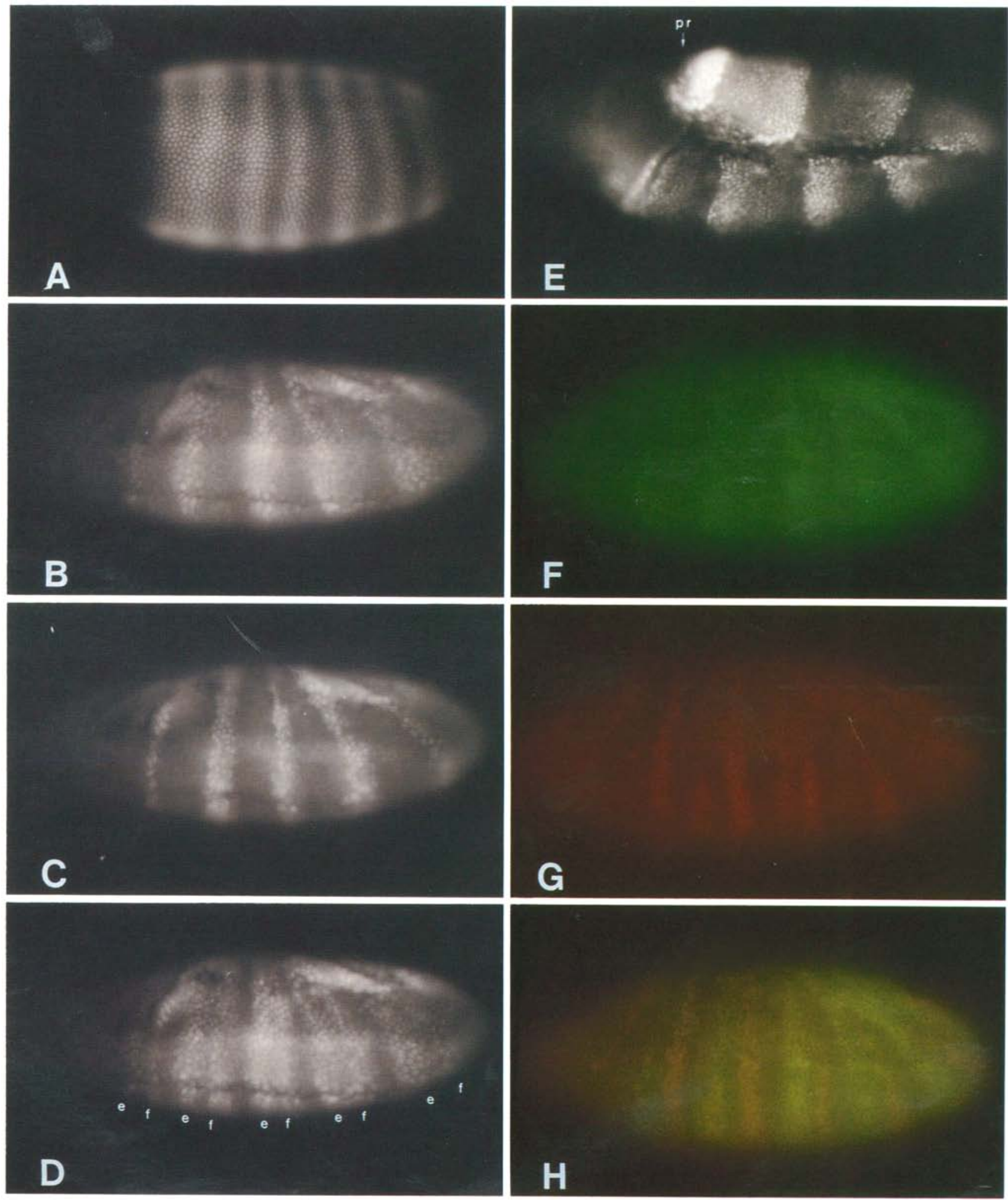

Figure 4. (See following page for legend.) 
are lost in wild-type embryos. ID19 homozygotes grown at $25^{\circ} \mathrm{C}$ show a less severe disruption of the eve pattern (Fig. 5F), which is similar to that observed for IIR59 mutants (see Fig. 3A).

It is possible that the altered eve patterns described above could involve abnormal protein stabilities. For example, the premature loss of eve products seen in ID19 mutants grown at $31^{\circ} \mathrm{C}$ could be due to an unstable, thermo labile protein. To test this, we have used in situ hybridization to analyze the eve RNA pattern in 3.77.17 mutants and in the protein null mutant R13. The RNA pattern observed in 3.77.17 homozygotes is virtually identical to the protein pattern shown in Figure 4. Prior to gastrulation, the stripes are unevenly spaced, such that stripes 1 and 2 are partially fused (Fig. 6A). During germ band elongation, each stripe is abnormally broad and persists for longer periods of development, as compared with those of wild-type embryos (Fig. 6B). The RNA pattern seen in R13 homozygotes is quite similar to the protein pattern in ID19 mutants grown at $31^{\circ} \mathrm{C}$. Young mutant embryos show partial pairwise alignments of adjacent stripes (Fig. 6C), and there is a premature loss of expression during gastrulation (Fig. 6D). This loss of expression appears to be tissue specific, in that transcripts persist in dorsal regions and in the ventral mesoderm for normal periods, but is prematurely lost in the ventral ectoderm.

\section{eve, ftz, and en expression in eve hypomorphs}

At first glance, the $f t z$ pattern appears essentially normal in eve hypomorphs, such as IIR59 and 3.77.17 homozygotes. However, when these mutants were doublestained with both anti-eve and anti-ftz antibodies, an alteration of the $f t z$ pattern became evident. In each eve mutant the seven $\mathrm{ftz}$ stripes are shifted to more anterior regions, thereby bringing adjacent $e v e$ and $f t z$ stripes closer together. The degree of this shift correlates with the strength of the eve allele, with weak mutants causing relatively minor shifts and stronger mutants causing more severe shifts. The disruptions of the en pattern that are observed in eve mutants correlate with this abnormal spacing of the eve and $f t z$ expression stripes.

Figure 3, A and B, shows a IIR59 mutant embryo that was stained with both anti-eve and anti-en antibodies. All 14 middle body en stripes are present but are not evenly spaced, as observed in wild-type embryos of similar age. For example, en stripes 3 and 4 are closer together, and an abnormally large gap separates stripes 4 and 5. This abnormal spacing of the en pattern results from an anterior shift of each even-numbered en stripe from its normal location in wild-type embryos. These shifts of the en pattern correlate with a shifting of each of the $f t z$ stripes (see below). Furthermore, the odd-numbered en stripes are somewhat broader than the evennumbered stripes (Fig. 3B-D). These broader stripes correlate with the broadening of the eve pattern seen in each of the weak eve mutants (i.e., Figs. 3A and 4B).

The en pattern becomes even more severely disrupted in advanced-stage IIR59 mutants. Adjacent en stripes partially fuse at the completion of germ band elongation and during germ band retraction. A similar situation is observed for ID19 homozygotes at $25^{\circ} \mathrm{C}$ and 3.77 .17 homozygotes (an example is shown in Fig. 3C,D). Such pairwise fusions of the en pattern correlate with the phenotypes of these mutants: The anterior portion of each en double stripe disappears after germ band retraction, resulting in one-half the normal number of middle body en stripes.

The strong eve hypomorphic allele, 3.77.17, causes somewhat more severe alterations of the $f t z$ and en patterns. The evolution of the $f t z$ pattern appears almost normal during blastoderm stages, although stripes 2 and 4 are abnormally broad (Fig. 4C). This correlates with broader gaps between adjacent eve stripes in this region (Fig. 4A). Double staining experiments show that each $\mathrm{ftz}$ stripe is shifted anteriorly, as observed in IIR59 mutants (Fig 4D). The eve/ftz double staining pattern observed in 3.77.17 mutants is similar to that observed for the $e v e$ pattern alone. The weak eve domain of staining observed within each broad double stripe eve band coincides with the new location of each $f t z$ stripe (Fig. $4 \mathrm{~B}-\mathrm{D}$ ). Each evelftz double stripe is separated by an abnormally large gap of cells that show little staining. Thus, the anterior margin of each eve stripe is quite close to the next more posterior $f t z$ stripe: eve stripe $1 / f t z$ stripe 1 -large gap-eve stripe $2 / f t z$ stripe $2-$ large gap, etc.

Figure 4. eve, ftz, and en expression in 3.77.17 mutants. Embryos are presented as described in the legend to Fig. 1. All embryos are homozygous for the 3.77.17 allele. $(A)$ eve expression in cellular blastoderm-stage embryo. The spacing of the stripes is uneven. In particular, stripes 1 and 2 are partially fused. $(B-D)$ Embryo at the onset of germ band elongation that was double-stained with anti-eve and anti-ftz antibodies. (B) Photographed to show eve staining. The stripes are much broader, as compared with those of wild-type embryos of the same age. Each stripe appears to contain a strongly stained anterior domain and a more weakly stained posterior domain. $(C)$ Photographed to show $f t z$ staining. Stripes 2 and 4 are abnormally broad. (D) Double exposure to show eve/ftz staining. Note that the spacing of adjacent $e v e(\mathrm{e})$ and $f t z|\mathrm{f}\rangle$ stripes is abnormal and gives the appearance of $e v e / f t z$ double stripe units. Such double stripes are separated by abnormally large gaps; compare with the wild-type embryo shown in Fig. 1B. $(E)$ eve expression in an embryo after germ band elongation. The stripes are quite broad, and as seen earlier, each appears to be composed of one strongly stained domain plus one weakly stained domain. Wild-type embryos of the same age have lost the eve stripes and show expression in a ring that surrounds the proctodeum $(\mathrm{pr})$. In 3.77 .17 mutants, the proctodeal staining is detected at the same time that the original stripes are seen. $(F-H)$ Embryo at the onset of germ band elongation that was double-stained with anti-eve and anti-en antibodies. $(F)$ Photographed to show eve expression. $(G)$ Photographed to show en expression. All stripes are abnormally broad, and there are pairwise alignments of adjacent stripes. The odd-numbered en stripes are incomplete in that dorsal regions show interruptions in staining. $(H)$ Double exposure to show both eve and en expression. The anterior margins of the eve stripes coincide with the oddnumbered en stripes. Note that dorsal regions of the odd-numbered en stripes express eve but show little or no staining with anti-en antibody. 
A
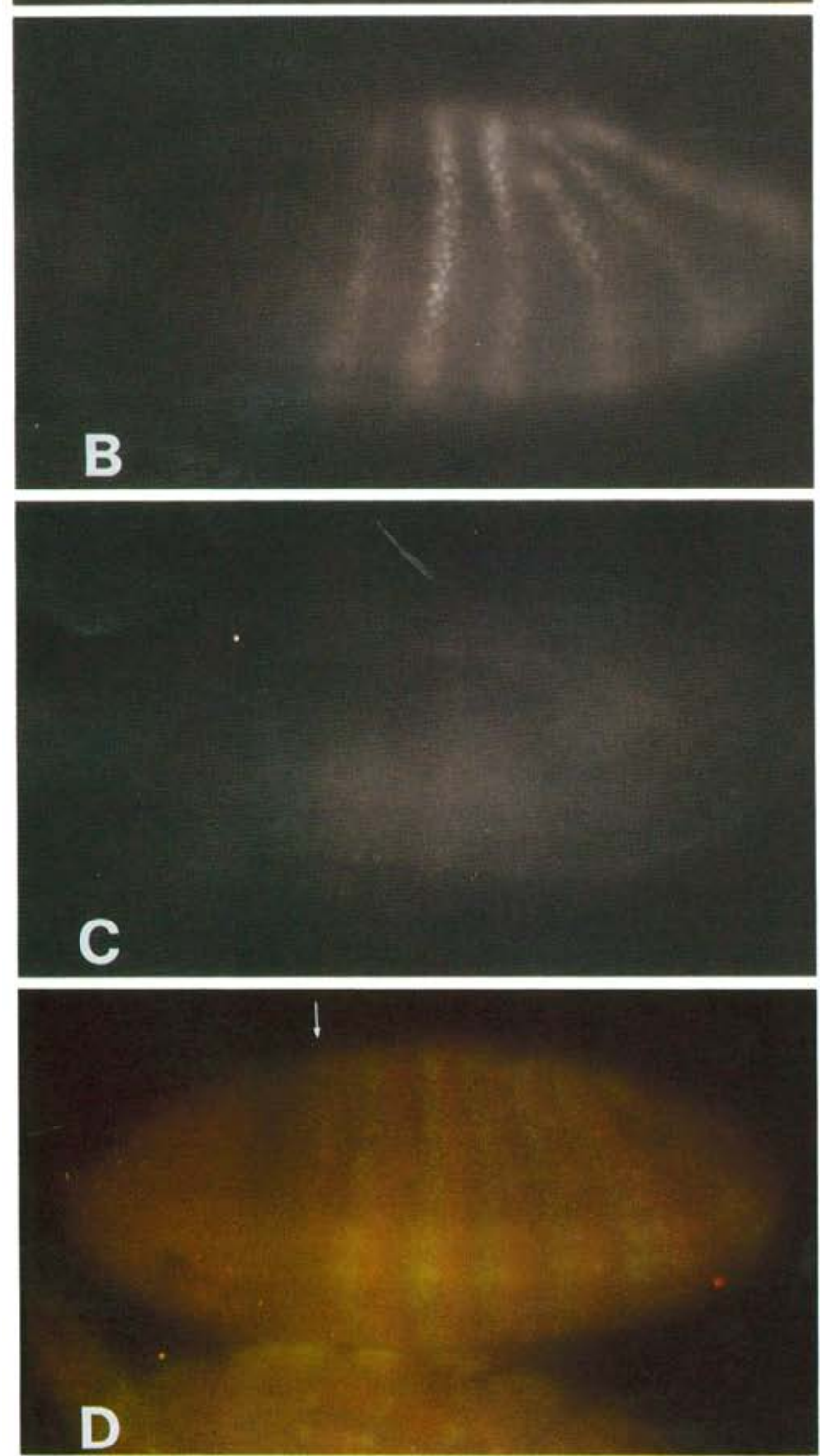
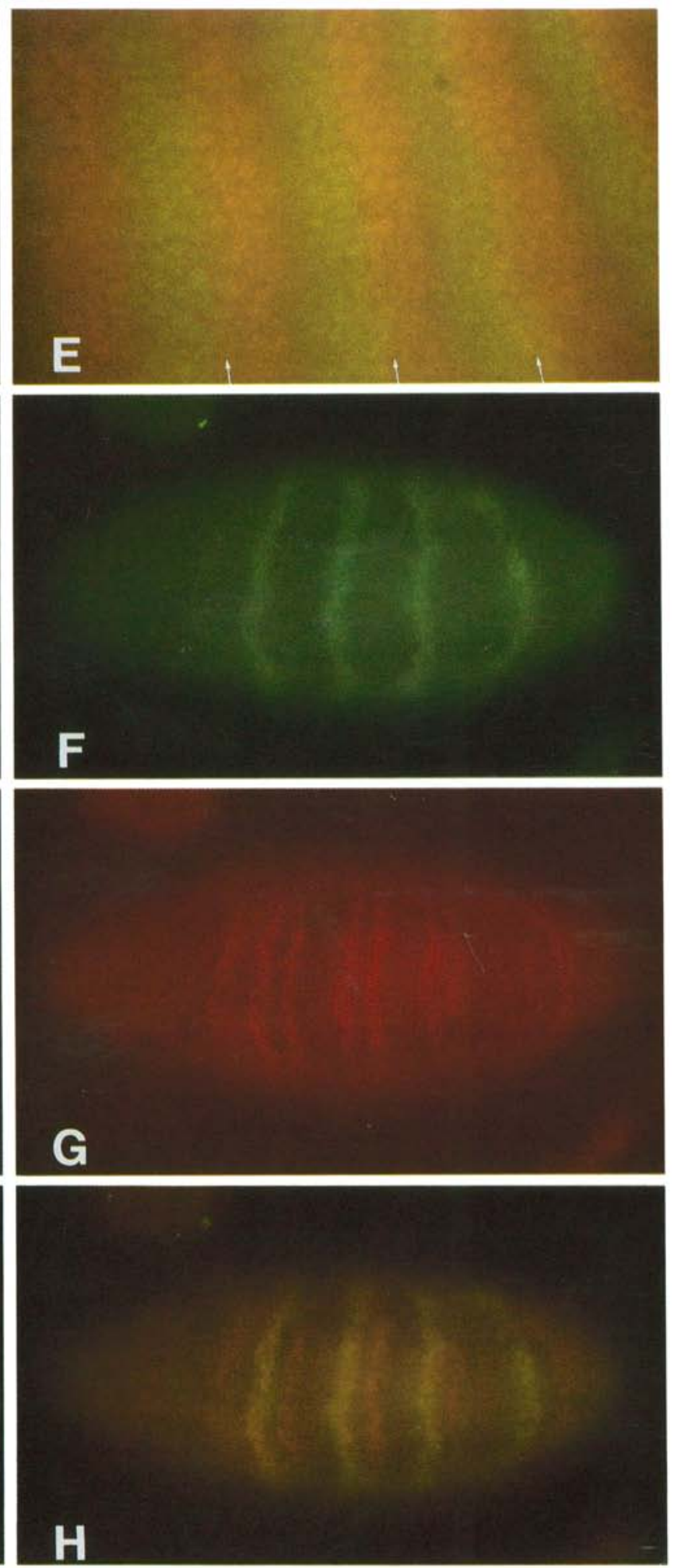

Figure 5. (See following page for legend.) 
The en pattern shows abnormalities in spacing and width that correlate with the altered $e v e$ and $f t z$ patterns (Fig. 4F-H). Partial pairwise alignments of adjacent en stripes are observed, such that $e n$ stripes 3 and 4 , and 5 and 6, etc., are brought closer together. The distances separating these partially fused $e n$ stripes correspond to the distances separating the anterior margins of $e v e$ and $f t z$ within each of the eve/ftz double stripes. The abnormal spacing of the en pattern is similar to that observed in IIR59 mutants (Fig. 3A,B). However, the pattern is somewhat more disrupted in 3.77.17 in that each en stripe is abnormally broad and includes an average of two cells instead of the normal one-cell stripes seen in wild-type embryos. This broadening of the en pattern correlates with the abnormally broad eve and $f t z$ stripes that are observed (see Fig. 4C,F). Normally, the anterior margin of each eve and ftz stripe contains peak levels of product and corresponds to the positions where en is activated. In 3.77.17 mutants, the first two to three cells of each $e v e$ and $f t z$ stripe contain equally high levels of product, resulting in broader en stripes.

Embryos homozygous for the ID19 mutation grown at $25^{\circ} \mathrm{C}$ show an anterior shifting of the $f t z$ pattern, which is similar to that observed in 3.77.17 and IIR59 mutants (data not shown). This shift results in the same type of pairwise alignments of adjacent en stripes (Fig. 5G,H). The en pattern that is observed has the following arrangement: en stripe 1, two-cell gap; stripe 2, four-cell gap; stripe 3, two-cell gap, etc. The patterns of eve, ftz, and en expression observed in each of the three eve hypomorphs are summarized in Figure 8.

\section{eve, $\mathrm{ftz}$, and en expression in eve null mutants}

It has been shown that a nearly normal seven-stripe $f t z$ pattern is established in embryos homozygous for the $e v e^{1.27}$ deletion (Carroll and Scott 1986; Harding et al. 1986). A similar situation is observed in ID19 homozygotes grown at $31^{\circ} \mathrm{C}$ (Fig. 5E). However, several abnormalities are detected by the onset of gastrulation, including the loss of the first $f t z$ stripe (Fig. 5D, arrow) and unequal spacing in the locations of the remaining six stripes. Double staining with anti-eve and anti-ftz antibodies shows that there is a strong anterior shifting of the $f t z$ pattern (Fig. 5D,E). This shift appears even more severe than that observed for eve hypomorphs, and the anterior margins of adjacent $e v e$ and $f t z$ stripes are separated by only one or two cells. A very clear eve/ftz double stripe of expression is observed, and adjacent double stripes are separated by large gaps of unlabeled cells (Fig. 5D). Despite the presence of $e v e$ and $f t z$ expression, en products are not detected in these regions at any time during development (Fig. 5C). The loss of the odd-numbered en stripes is the result of inactive eve products, whereas the failure to initiate the even-numbered en stripes is probably due to the abnormal positioning of the $f t z$ pattern (see below).

Further evidence that the anterior shifting of the $f t z$ pattern is more severe in eve null mutants, as compared with eve hypomorphs, was obtained by comparing the en pattern in ID19 mutants grown at different temperatures. As discussed above, the wild-type en pattern consists of a series of 14 evenly spaced stripes in the middle body regions of gastrulating embryos: en stripe 1, threecell gap; en stripe 2, three-cell gap, etc. Such a pattern is also observed in gastrulating ID19 homozygotes grown at $18^{\circ} \mathrm{C}$ (Fig. $7 \mathrm{~A}$ ). Each en stripe corresponds to the anteriormost cell of each $e v e$ and $f t z$ stripe and, therefore, serves as a marker for the relative positions of the eve and $f t z$ patterns in ID19 mutants grown at different temperatures. As shown above, mutants grown at $25^{\circ} \mathrm{C}$ show a one-cell shift of each $f t z$ stripe, resulting in pairwise alignments of en. Instead of observing evenly spaced en stripes, the pattern has the following arrangement: en stripe 1, two-cell gap; en stripe 2, four-cell gap; en stripe 3, two-cell gap; en stripe 4, four-cell gap, etc. (Fig. 7B). en stripes are rarely detected at $31^{\circ} \mathrm{C}_{\text {; }}$ however, weak, transient expression is detected for several of the stripes at slightly lower temperatures $\left(29^{\circ} \mathrm{C}\right)($ Fig. $7 \mathrm{C})$. These stripes are paired more strongly than those seen in mutants grown at lower temperatures. Larger gaps separate adjacent en double stripes, which show the following pattern: en stripe 1, one-cell gap; en stripe 2, five-cell gap; en stripe 3, one-cell gap, etc.

Figure 5. eve, $f t z$, and en expression in ID19 mutants. Embryos are presented as in Figs. 1 and 4. (A-E) ID19 homozygotes grown at $31^{\circ} \mathrm{C}$, which show the null phenotype. $(F-H)$ Mutants grown at $25^{\circ} \mathrm{C}$, which show the hypomorphic pair-rule phenotype. $(A)$ eve expression in null mutant. The stripes are unevenly spaced, and the first stripe is narrower and of weaker intensity than normal. $(B)$ eve expression in null mutant at the onset of germ band elongation. The stripes have begun to disappear prematurely, and have not sharpened properly. The stripes appear somewhat broader, and the anterior margin of each stripe is not as sharp as in wild type. Stripes 1,5 , and 6 are the first to disappear, and expression is lost in the ventrolateral ectoderm prior to repression in the mesoderm and dorsal ectoderm. $(C)$ en expression in the embryo shown in $B$. Staining is not observed above background levels. $(D)$ eve and $f t z$ expression in a gastrulating null mutant. The first $e v e$ and $f t z$ stripe have nearly disappeared (arrow), and the remaining stripes are unevenly spaced. Double $e v e / f t z$ units are observed, with abnormally large gaps separating adjacent units. $(E)$ High-magnification view of $e v e / f t z$ double staining in a null mutant at the cellular blastoderm stage. The overlap between adjacent $e v e$ (green) and $f t z$ (red) stripes results in the appearance of nuclei with a yellow color (arrows). Abnormally large gaps of unlabeled nuclei occur between adjacent $e v e / f t z$ double units. $(F-H)$ Gastrulating ID19 hypomorph $\left(25^{\circ} \mathrm{C}\right)$ double stained with eve and en antibodies. $(F)$ Photographed to show eve staining. There is a premature loss of the first expression stripe. $(G)$ Photographed to show en staining. Stripes 3 and 4 , and 5 and 6 , etc., are spaced in pairwise alignments. $(H)$ Photographed to show eve and en staining. The odd-numbered en stripes coincide with the anterior margin of each eve stripe. 

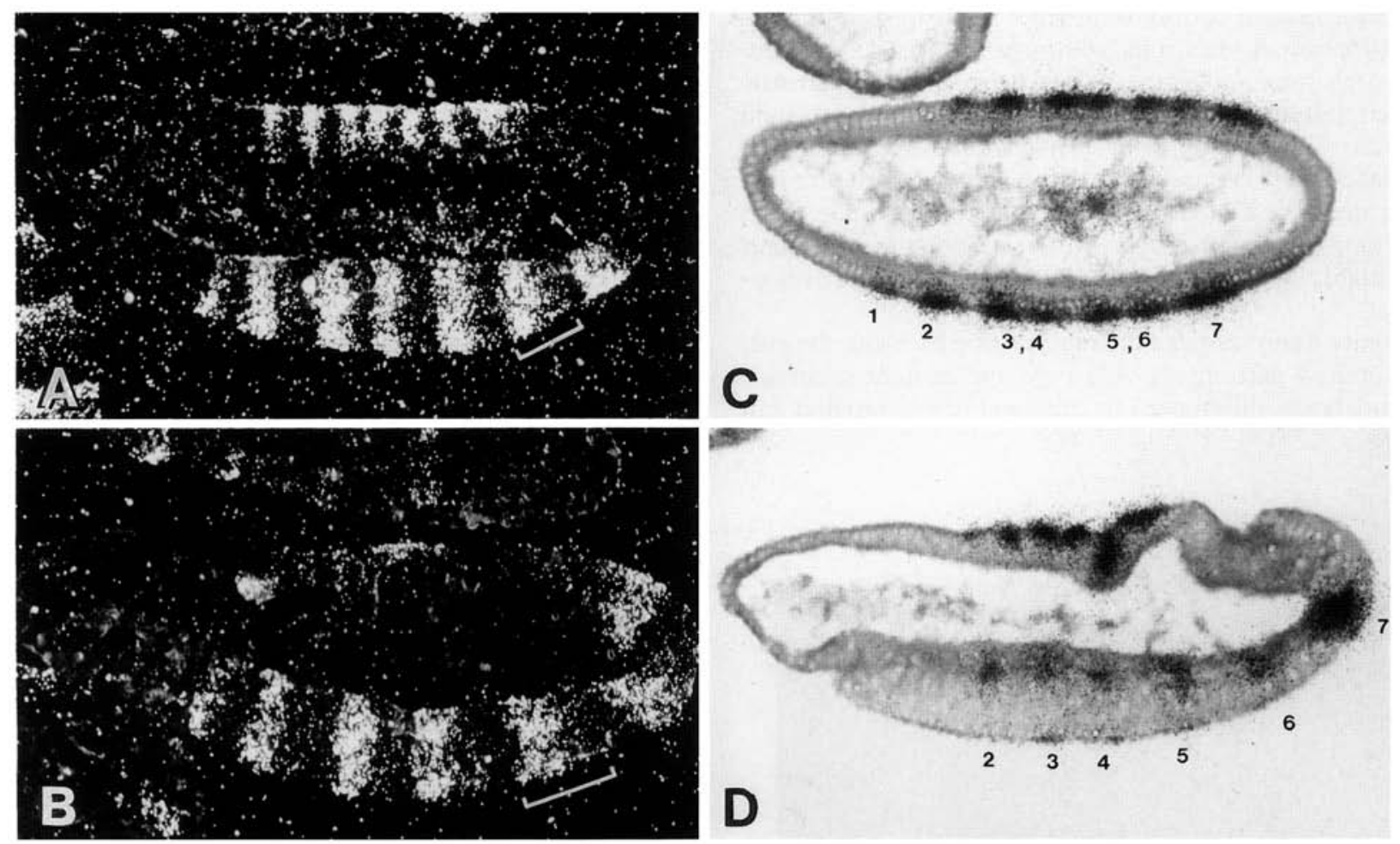

Figure 6. In situ localization of eve RNAs in 3.77 .17 and R13 mutants. Sagittal sections of embryos are oriented so that anterior is to the left and dorsal is up. All sections were hybridized with an eve cDNA probe. $(A, B) 3.77 .17$ homozygotes; $(C, D)$ R13 homozygotes. (A) Dark-field photomicrograph of a gastrulating 3.77.17 mutant. Seven broad stripes of $e v e$ expression are detected. Stripe 1 is reduced in width and intensity as compared with the others, and there are weak, pairwise alignments of stripes 1 and 2 , and 3 and 4 . The stripes are considerably broader than those seen in wild-type embryos of the same age. $(B)$ Dark-field photomicrograph of a 3.77 .17 mutant after elongation of the germ band. The stripes are abnormally broad. The eve stripes are virtually absent by this time during wild-type development. Note the double-unit appearance of some of the stripes (brackets in $A$ and $B$ ). As seen by antibody staining (Fig. 4E), each stripe contains a strongly stained anterior domain plus a more weakly stained posterior domain. $(C) \mathrm{R} 13 \mathrm{mutant}$ during cleavage cycle 14 . The stripes are unevenly spaced and show pairwise alignments. Note that stripe 1 is weaker than the others. $(D)$ R13 mutant at the onset of germ band elongation. Stripe 1 is no longer detected in ventral regions, and the remaining stripes are not evenly spaced (note pairwise alignment of stripes 3 and 4). All stripes show a premature loss of expression in the ventral ectoderm.

\section{Discussion}

The studies described here, and in previous reports (Carroll and Scott 1986; Harding et al. 1986; Howard and Ingham 1986; Macdonald et al. 1986; DiNardo and O'Farrell 1987) suggest that eve influences the segmentation pattern by either directly or indirectly regulating its own expression, as well as the expression of two other segmentation genes, $f t z$, and en. eve appears to regulate its own expression positively, as well as participate in the activation of the odd-numbered en stripes. eve also appears to repress the expression of $f t z$ and, thereby, indirectly influence the even-numbered en stripes. There is a close correlation between the extent to which the eve, ftz, and en patterns are disrupted in a given eve mutant and the severity of the mutant based on genetic analysis of phenotype (Nüsslein-Volhard and Wieschaus 1980; Nüsslein-Volhard et al. 1985), and on molecular studies of the cloned mutant alleles.

\section{Positioning the $\mathrm{ftz}$ stripes}

Only the null mutations, which abolish eve gene function, disrupt eve, ftz, and en expression. One of these mutants, R13, appears to be a protein null (Frasch et al. 1987), and the other, ID19 (raised at $31^{\circ} \mathrm{C}$ ), contains an amino acid substitution within a region of the eve homeo domain that is likely to play an important role in DNA binding (see below). Weak eve mutants (i.e., hypomorphs) do not eliminate the odd-numbered en stripes and cause less severe disruptions of the eve and $f t z$ patterns. We propose that the principal effect these mutations have on the segmentation pattern involves a failure to repress $f t z$ expression in posterior regions of the odd-numbered parasegments (for the definition of a parasegment, see Martinez-Arias and Lawrence 1985). This results in an anterior shifting of the anterior $f t z$ margins which, in turn, causes pairwise fusions of adjacent en stripes. It is not clear whether this shift of the 
anterior margin results in broader $f t z$ stripes. It appears that $f t z$ stripes of normal widths are shifted in their entirety to more anterior positions. Perhaps other pair-rule genes that are known to influence the $f t z$ pattern, such as hairy and/or runt, are also shifted in eve mutants. Alternatively, it is possible that the shifting of the ftz pattern involves a broadening of each $f t z$ stripe due to an anterior expansion. The posterior margins of $f t z$ stripes are highly dynamic and sharpen rapidly during development.

Figure 8 summarizes the relationship between the $e v e$, $f t z$, and en patterns in wild-type and mutant embryos. Quantitative differences in the level of eve product can
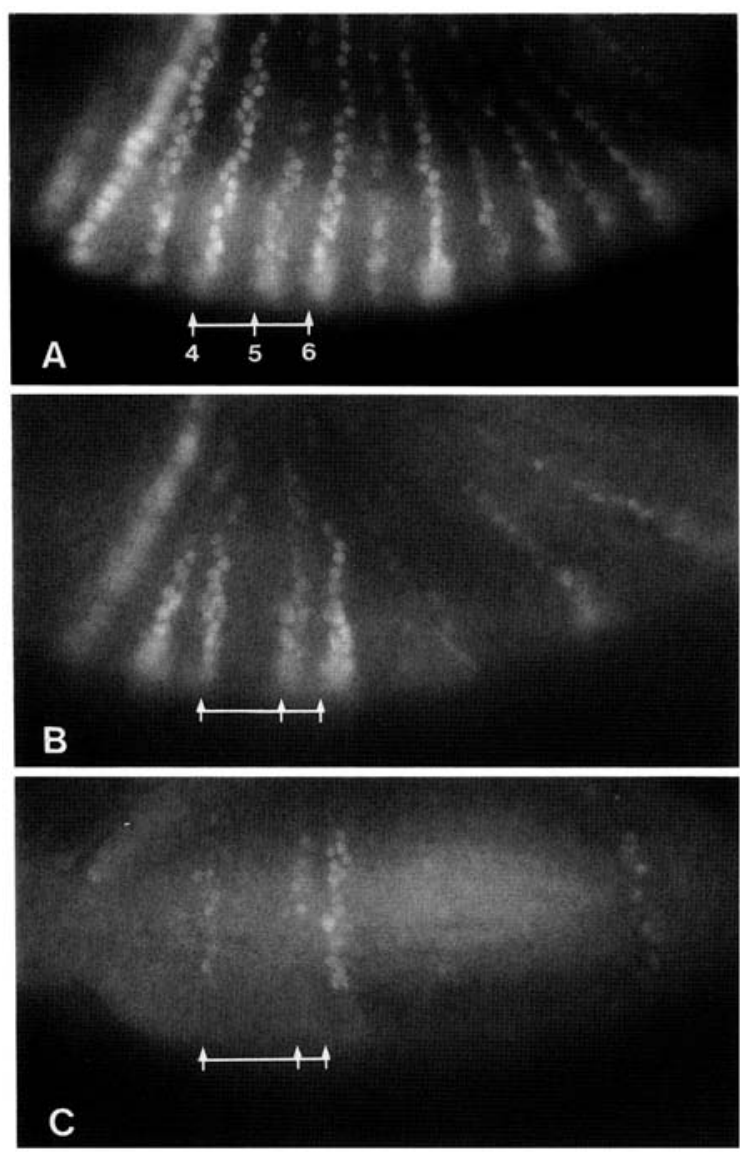

Figure 7. en expression in ID19 mutants grown at different temperatures. Gastrulating ID19 homozygotes were stained with anti-en antibody. The bars indicate en stripes 4, 5, and 6 . (A) Mutant grown at $18^{\circ} \mathrm{C}$. The en pattern is normal and adjacent stripes are evenly spaced. $(B)$ Mutant grown at $25^{\circ} \mathrm{C}$. en stripes are not evenly spaced and show pairwise alignments due to the anterior shifting of the even-numbered stripes. For example, stripes 3 and 4 and 5 and 6 are paired. An abnormally large gap separates adjacent paired units, as seen for the region between stripes 4 and 5. $(\mathrm{C})$ Mutant grown at $29^{\circ} \mathrm{C}$. Most of the en stripes do not appear at this temperature. However, a severe shift of the remaining stripes is observed. This shift is stronger than that observed at $25^{\circ} \mathrm{C}$. be seen among the cells that comprise a stripe (Frasch and Levine 1987). During cellularization, the posterior region of each eve stripe overlaps slightly with the initial anterior border of adjacent $f t z$ stripes. In wild-type embryos, both eve and ftz products are ultimately lost in this region of overlap. At the onset of gastrulation, en stripes come to be expressed at the sharpened anterior margin of each eve and ftz stripe (Lawrence et al. 1987; see Fig. 1). In weak eve mutants, such as ID19 homozygotes grown at $25^{\circ} \mathrm{C}$, ftz expression is not lost at its initial anterior border within the posterior region of the odd-numbered parasegments. This results in an anterior shift of the $f t z$ pattern relative to $e v e$ and pairwise alignments of adjacent en stripes. Stronger eve mutants cause more severe shifts of the $f t z$ pattern.

We propose that the failure of $f t z$ to activate the evennumbered en stripes in eve null mutants results from the severe shift of the $f t z$ pattern. Perhaps $f t z^{+}$products are unable to promote en expression in these new locations of the embryo, as summarized in Figure 8. According to this model, the activation of en might involve the combined activities of $f t z$ and a second pair-rule gene, $\mathrm{X}$. The pattern of $\mathrm{X}$ expression might overlap with the anterior half of each $f t z$ stripe. In weak eve mutants, such as ID 19 homozygotes grown at $25^{\circ} \mathrm{C}$, the $f t z$ pattern is shifted by only one or two cells, which are still within the domain of $\mathrm{X}$ expression. Consequently, $\mathrm{ftz}$ can function in these new positions to activate en. However, the $f t z$ pattern is shifted outside the limits of $\mathrm{X}$ expression in null mutants (e.g., ID19 at $31^{\circ} \mathrm{C}$ ). It has been noted that eve ${ }^{-}$, odd-skipped ${ }^{-}$(odd) double mutants express seven en stripes instead of none (DiNardo and O'Farrell 1987). Perhaps odd mutations cause a shift of the $\mathrm{X}$ pattern so that it is brought back in register with the shifted $f t z$ stripes in eve, odd double mutants. As a result, the ftz domain of en expression is restored. It has been proposed that the pair-rule gene odd-paired (opa) might act in concert with $f t z$ to activate en (Ingham et al. 1988), thus fulfilling the role of gene $X$.

An alternative explanation for the loss of the evennumbered en stripes in eve- embryos concerns the occurrence of weak, transient eve stripes within the ftz domain during normal development (Macdonald et al. 1986; Frasch et al.1987). The eve pattern consists of a total of 14 evenly spaced stripes for a brief period following gastrulation. It is possible that the activation of the even-numbered en stripes requires the combined action of $f t z$ products and these low levels of eve. One drawback to this proposal is the observation that en expression is initiated within the $f t z$ domain prior to the detection of the weak eve stripes (DiNardo et al. 1985; Kornberg et al. 1985; Macdonald et al. 1986; Frasch et al. 1987). In addition, it is difficult to invoke a role for the weak eve stripes in activating en because the even-numbered en stripes reappear in $\mathrm{eve}^{-}$, odd- double mutants (see above). Finally, we do not detect the weak eve stripes in ID 19 mutants grown at $25^{\circ} \mathrm{C}$ or in IIR59 mutants, suggesting that their loss does not interfere with the activation of $e n$ by $f t z$. For these reasons, we prefer the ' $f t z$ shift' mechanism shown in Figure 8. 


\section{Disruptions of other segment polarity genes}

None of the weak eve mutations results in a failure of eve to activate the odd-numbered en stripes, which disappear relatively late in development /after germ band retraction). It is likely that these sites of expression are lost as an indirect consequence of reduced eve gene function. Segment polarity genes such as wg and patched have been shown to be required for the maintenance of en expression during advanced stages of development (DiNardo et al. 1988; Martinez-Arias et al. 1988). The establishment of the $w g$ pattern depends on regulatory interactions with eve and ftz (Ingham et al. 1987), and it is anticipated that the expression of $w g$ and, perhaps, other segment polarity genes is abnormal in eve mutants. Altered activities of one or more segment polarity genes might be ultimately responsible for the loss of the odd-numbered en stripes.

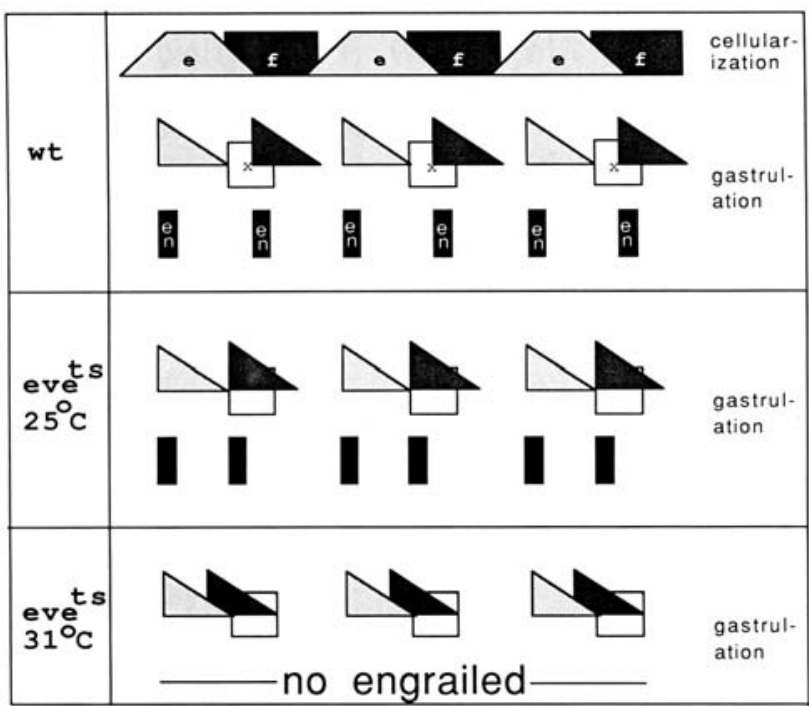

Figure 8. Summary of the eve, $f t z$, and en patterns. The eve and $f t z$ patterns overlap slightly in cellularizing wild-type embryos, such that the posterior region of each eve stripe contains low levels of eve/ftz products. Repression of $f t z$ within this region of overlap would lead to a posterior shift in the anterior margin of each $f t z$ stripe during gastrulation. At this time, there is also a posterior to anterior loss of eve and $f t z$ expression within each stripe, giving peak levels of product at the anterior margins. en is activated within the cells of each eve and $f t z$ stripe that contains these peaks of expression. We propose that the activation of the even-numbered en stripes involves a combination of $f t z$ and a second pair-rule gene, called $\mathrm{X}$. In weak eve mutants (e.g., IIR59 or ID19 at $25^{\circ} \mathrm{C}$ ) there is sufficient $e v e^{+}$ gene activity for initiating the odd-numbered en stripes but an insufficient level to repress $f t z$ in the region of eve/ftz overlap. This results in an anterior shift of each $f t z$ stripe and, consequently, in the pairwise alignments of adjacent en stripes. In null mutants (e.g., $\mathrm{R} 13$ or $\mathrm{ID} 19$ at $31^{\circ} \mathrm{C}$ ) there is insufficient $e v e$ activity for initiating the odd-numbered en stripes. In addition, there is a complete failure to repress $f t z$, resulting in a strong anterior shift of the $f t z$ pattern. This shift is so severe that $f t z$ no longer overlaps with gene $X$, and $f t z$ is now unable to activate the even-numbered en stripes.
The shifting of the ftz pattern observed in eve mutants suggests that quantitative differences in the level of eve product within an expression stripe might be functionally significant. We have shown that there is a correlation between the extent to which the $f t z$ pattern is shifted in different eve mutants and the level of eve $e^{+}$ product normally found in the affected cell. The weakest eve mutants cause a shifting of $\mathrm{ftz}$ into the posteriormost cells of the odd-numbered parasegments, which normally show the lowest level of $e v e^{+}$products. More severe mutations cause a stronger anterior shift into regions that normally contain higher levels of product.

\section{eve autoregulation}

Each of the eve mutants that was examined displays an abnormal pattern of eve expression. The disruptions that are observed suggest that eve autoregulation is required to maintain high levels of expression during gastrulation and germ band elongation. It is possible that such autoregulation contributes to the observed sharpening of the eve stripes during these periods of development (Frasch et al. 1987).

The two null mutations that were examined, R13 and ID19 (at $31^{\circ} \mathrm{C}$ ), show a premature loss of eve expression stripe 1, the general loss of eve products from the ventral ectoderm, and abnormal spacing between adjacent stripes. For the temperature-sensitive ID19 mutation, these alterations could result, in principle, from a thermolabile eve protein. More convincing evidence that $e v e^{+}$gene activity is required for the maintenance of eve expression was obtained by analyzing the eve RNA pattern in R13 homozygotes, which do not express the eve protein (Frasch et al. 1987). The eve RNA pattern observed in these mutants is similar to the eve protein pattern in ID19 mutants grown at $31^{\circ} \mathrm{C}$ (cf, Figs. $5 \mathrm{~A}, \mathrm{~B}$ and 6C,Dl.

We have shown that the IIR59 and ID19 mutations cause single amino acid substitutions within the eve homeo box (Fig. 2). For ID19, the substitution occurs within a highly conserved region of the homeo box. The location of this substitution near the putative recognition helix is consistent with the notion that at restrictive temperatures the mutant protein is unable to bind with appropriate cis regulatory elements, thereby causing a breakdown in autoregulation. All known Drosophila homeo boxes contain a basic residue at the position where the ID19 mutation maps, either an arginine (the overwhelming majority) or a lysine (observed only for the en and invected genes). It is possible that the highly conserved basic residue within this region of the homeo box is important for optimizing protein-DNA contact through an electrostatic interaction with the phosphate backbone of DNA. Perhaps the replacement of the arginine by a less basic residue reduces the stability of eve/DNA complexes.

The IIR59 mutation maps near the amino-terminal end of the homeo box, which is a region that might not be directly involved in DNA binding. The mutation substitutes an isoleucine residue for a threonine at position 
75 of the eve protein-coding sequence (Fig. 2). The majority of known homeo box genes in Drosophila (12 of 17) contain a threonine residue at this position. Chou and Fasman analysis predicts an $\alpha$-helix just downstream from this position, spanning residues $81-90$ of the $e v e$ protein. The function of this helix is not known, although it has been proposed that it might be involved in protein-protein contacts and multimerization (P.H. O'Farrell, pers. comm.). Perhaps the IIR59 mutation disrupts this $\alpha$-helix and indirectly impairs DNAbinding activity due to a breakdown in a cooperative protein-protein interaction.

The requirement of $\mathrm{eve}^{+}$gene activity for high levels of $e v e$ expression during development might be similar to the situation described previously for $f t z$. The $f t z$ promoter includes a distal 'enhancer' element that maintains high levels of $f t z$ expression in the ectoderm of embryos undergoing gastrulation and germ band elongation (Hiromi et al. 1985; Hiromi and Gehring 1987). The activity of this enhancer depends on $f t z^{+}$gene activity, and it has been proposed that the $f t z$ protein binds selectively to cis elements within the enhancer. It has been shown that the eve protein binds with high affinity to sites within the eve promoter, and it is possible that one or more of these binding sites mediates the eve autoregulatory interaction shown here (Hoey and Levine 1988).

The results presented here are also compatible with the possibility that eve autoregulation is indirect and mediated by products encoded by other pair-rule genes. Previous studies have shown that hairy and runt participate in the maintenance and sharpening of the eve pattern during gastrulation and germ band elongation (Frasch and Levine 1987). Perhaps eve mutants disrupt the activities of these genes which, in turn, cause altered patterns of eve expression. Several lines of evidence favor a direct mechanism for eve autoregulation. First, the disruption of the hairy pattern observed in $e v e^{-}$embryos is rather subtle and does not obviously account for the altered eve patterns seen in eve mutants (Rushlow et al. 1987). Second, the eve 3.77.17 and null mutations alter the eve pattern prior to the completion of cellularization (i.e., Figs. 4A and $6 \mathrm{C}$ ), which is well before the time when runt and hairy have been shown to exert an influence on the eve pattern (Frasch and Levine 1987). Finally, we have recently obtained evidence that a distal region of the eve promoter, from $-6 \mathrm{~kb}$ to $-5 \mathrm{~kb}$ upstream from the transcription start site mediates eve autoregulation in vivo (K. Harding, T. Hoey, R. Warrior, and $M$. Levine, in prep.).

Is autoregulation important for the refinement and sharpening of the $e v e$ and/or $f t z$ patterns during development? There is a gradual loss of $e v e$ and $f t z$ expression, first in posterior cells and then in more anterior regions, of each expression stripe during development (Frasch et al. 1987; Lawrence et al. 1987). It is conceivable that autoregulation plays a role in this process. Perhaps there is a general repressor that is responsible for the gradual loss of $e v e$ and $f t z$ expression. Positive autoregulation might delay the time when such a repressor succeeds in eliminating expression. The anterior cells within each eve stripe start out with higher levels of product (see Fig. 8) and may therefore show longer persistence of expression due to positive feedback. Consistent with this proposal is the demonstration that the 3.77 .17 mutant interferes significantly with the refinement of the eve pattern during advanced stages. Broad bands of eve expression are observed in 3.77.17 mutants at times when sharp stripes are normally observed in wild-type embryos. Thus, it appears that the 3.77 .17 protein, in some way, maintains high levels of expression even in those cells of each eve expression stripe that normally show a rapid loss of expression. It is as though the defective 3.77.17 protein promotes more efficient autofeedback in some way. The 3.77.17 protein lacks the carboxy-terminal one-third of the native eve protein, and perhaps this loss 'derepresses' the normal autoregulatory activity of the protein and makes it unresponsive to negative control factors.

Other explanations can be envisioned. For example, perhaps the 3.77 .17 protein is more stable than the wildtype eve protein, thereby promoting eve transcription for a longer time. Alternatively, it is possible that the 3.77.17 RNA is more stable than the wild-type eve transcript. According to this latter model, the sharpening of the eve pattern observed during normal development might be a post-transcriptional process depending on highly unstable RNAs and differential degradation.

\section{Experimental procedures}

\section{Cloning mutant alleles}

Homozygous ID19 and IIR59 embryos were identified and hand-picked on the basis of their cuticular phenotypes. Genomic DNA was prepared from mutant embryos, digested with EcoRI, and inserted into the unique RI site of the $\lambda$ EMBL4 vector. The libraries were screened by standard techniques using an eve cDNA fragment as probe. A strain polymorphism in the ID19 and IIR59 chromosomes results in the loss of one of the three AvaII sites in the wild-type eve-coding sequence. This site is present in the wild-type copy of the gene carried on the balancer chromosome. Consequently, Avall digestion permitted rapid and unambiguous identification of the mutant eve alleles and distinguished these from copies of the wild-type gene that could contaminate the libraries.

\section{Nucleotide sequence analysis}

Each of five different genomic fragments from the two mutant alleles was cloned into the mpl8 and mp19 M13 vectors (Yanish-Perron et al. 1985): (1) a 1.1-kb PstI fragment; (2) a 650bp XhoI-SphI fragment; (3) a 380-bp SphI-PstI fragment; (4) a 280-bp SphI-Pst fragment; and, (5) a 1-kb PstI-EcoRI fragment. In this way, the sequence of both strands of the entire eve-transcribed region was determined. Sequencing was done by the dideoxy method (Sanger et al. 1977), using a modified T7 polymerase called Sequenase (U.S. Biochemicals). A total of four nucleotide substitutions were identified in the sequence of the two mutant alleles, when compared to our previously published wild-type sequence (Frasch et al. 1987). Three of the four changes relative to the wild-type sequence are the same in the IIR59 and ID19 sequences. These probably represent strain polymorphisms; two are located in third positions of the reading frame and do not result in amino acid changes, and one 
is a first position change in codon 300 , which converts a leucine (CTC) to a valine (GTC). This latter change corresponds to a second wild-type sequence of eve (Macdonald et al. 1986), which is derived from a different Drosophila strain (Canton S) than our wild-type sequence (Ore-R). The IIR59 and ID19 sequences differ from each other and from the wild-type sequence in the fourth nucleotide changes, which cause amino acid substitutions in the homeo box (Fig. 2). It is not surprising that IIR59 and ID19 possess the same strain polymorphisms because the two eve mutations were obtained in the same mutagenesis screen (Nüsslein-Volhard et al. 1985).

\section{Antibody staining}

Staged embryos from wild-type and balanced mutant stocks were fixed and stained with antibodies, as described in Frasch et al. (1987). For double-staining experiments, the embryos were incubated with mixtures of rabbit anti-eve antibodies (affinity purified) and a mouse anti-ftz serum (diluted $1: 30$ ) or an en mouse monoclonal antibody. Detection was done after incubating in a mixture of FITC-conjugated goat anti-rabbit antibodies and TRITC-conjugated goat anti-mouse antibodies (purchased from Jackson Immuno Research). Double-stained embryos were mounted in a mixture of $0.3 \% n$-propylgallate and $0.15 \mathrm{mg} / \mathrm{ml}$ of $p$-phenylenediamine in glycerol.

\section{Acknowledgments}

We thank Tom Kornberg, Corey Goodman, and Chris Doe for providing the en monoclonal antibody and Chris Doe for the anti- $f t z$ antibody. We are grateful to Christianne Nüsslein-Volhard for the eve mutants and to Li Ya Shen and Kate Harding for help with the in situ hybridization experiments. This work was funded by a grant from the National Institutes of Health. M.F. was supported by a postdoctoral fellowship from the Deutsche Forschungsgemeinschaft.

\section{References}

Akam, M. 1987. The molecular basis for metameric pattern in the Drosophila embryo. Development 101: 1-22.

Bienz, M. and G. Tremml. 1988. Domain of Ultrabithorax expression in Drosophila visceral mesoderm from autoregulation and exclusion. Nature 333: 576-578.

Carroll, S.B. and M.P. Scott. 1985. Localization of the fushi tarazu protein during Drosophila embryogenesis. Cell 43: $47-57$

Carroll, S.B. and M.P. Scott. 1986. Zygotically-active genes that affect the spatial expression of the fushi tarazu segmentation gene during early Drosophila embryogenesis. Cell 45: $113-126$.

Desplan, C., J. Theis, and P.H. O'Farrell. 1985. The Drosophila developmental gene, engrailed, encodes a sequence-specific DNA binding activity. Nature 318: 630-635.

DiNardo, S., J.M. Kuner, J. Theis, and P.H. O'Farrell. 1985. Development of embryonic pattern as revealed by accumulation of the nuclear engrailed protein. Cell 43: 59-69.

DiNardo, S. and P.H. O'Farrell. 1987. Establishment and refinement of segmental pattern in the Drosophila embryo: Spatial control of engrailed expression by pair-rule genes. Genes Dev. 1: 1212-1225.

DiNardo, S., E. Sher, J. Heemskerk-Jongens, J.A. Kassis, and P.H. O'Farrell. 1988. Two-tiered regulation of spatially patterned engrailed gene expression during Drosophila embryogenesis. Nature 332: 604-609.
Fjose, A., W.J. McGinnis, and W.J. Gehring. 1985. Isolation of a homoeo box-containing gene from the engrailed region of Drosophila and the spatial distribution of its transcripts. Nature 313: 284-289.

Frasch, M., T. Hoey, C. Rushlow, H. Doyle, and M. Levine. 1987. Characterization and localization of the even-skipped protein of Drosophila. EMBO I. 6: 749-759.

Frasch, M. and M. Levine. 1987. Complementary patterns of even-skipped and fushi tarazu expression involve their differential regulation by a common set of segmentation genes in Drosophila. Genes Dev. 1: 981-995.

Hafen, E., A. Kuroiwa, and W.J. Gehring. 1984. Spatial distribution of transcripts from the segmentation gene fushi tarazu of Drosophila. Cell 37: 825-831.

Harding, K., C. Rushlow, H.J. Doyle, T. Hoey, and M. Levine. 1986. Cross-regulatory interactions among pair-rule genes in Drosophila. Science 233: 953-959.

Hartenstein, V., G.M. Technau, and J.A. Campos-Ortega. 1985. Fate mapping in wild-type Drosophila melanogaster. III. A fate map of the blastoderm. Wilhelm Roux's Arch. Dev. Biol. 194: 213-216.

Hiromi, Y., A. Kuroiwa, and W.J. Gehring. 1985. Control elements of the Drosophila segmentation gene fushi tarazu. Cell 43: 603-613.

Hiromi, Y. and W.J. Gehring. 1987. Regulation and function of the Drosophila segmentation gene fushi tarazu. Cell 50: $963-974$.

Hoey, T. and M. Levine. 1988. Divergent homeo box proteins recognize similar DNA sequences in Drosophila. Nature 332: 858-861.

Hoey, T., R. Warrior, J. Manak, and M. Levine. 1988. The DNA binding activities of the Drosophila even-skipped protein are mediated by its homeo domain and influenced by protein context. Mol. Cell Biol. 8: 4598-4607.

Howard, K. and P.W. Ingham. 1986. Regulatory interactions between the segmentation genes fushi tarazu, hairy, and engrailed in the Drosophila blastoderm. Cell 44: 949-957.

Ingham, P.W., N.E. Baker, and A. Martinez-Arias. 1988. Regulation of segment polarity genes in the Drosophila blastoderm by fushi tarazu and even-skipped. Nature 331: 73-75.

Kornberg, T. 1981. engrailed: A gene controlling compartment and segment formation in Drosophila. Proc. Nat1. Acad. Sci. 78: 1095-1099.

Kornberg, T., I. Siden, P.H. O'Farrell, and M. Simon. 1985. The engrailed locus of Drosophila: In situ localization of transcripts reveals compartment-specific expression. Cell 40: $45-53$.

Laughon, A. and M.P. Scott. 1984. Sequence of a Drosophila segmentation gene: Protein structure homology with DNA binding proteins. Nature 310: 25-31.

Lawrence, P.A. and G. Morata. 1976. Compartments in the wing of Drosophila: A study of the engrailed gene. Dev. Biol. 50: 321-337.

Lawrence, P.A., P. Johnston, P. Macdonald, and G. Struhl. 1987. Borders of parasegments in Drosophila embryos are delimited by the fushi tarazu and even-skipped genes. Nature 328: $440-442$.

Levine, M. and K. Harding. 1987. Spatial regulation of homeo box gene expression in Drosophila. Oxf. Surv. Eukaryotic Genes 5: 116-142.

Macdonald, P.M., P.W. Ingham, and G. Struhl. 1986. Isolation, structure, and expression of even-skipped: A second pairrule gene of Drosophila containing a homeo box. Cell 47: 721-734.

Martinez-Arias, A. and P.A. Lawrence. 1985. Parasegments and compartments in the Drosophila embryo. Nature 313: 639- 


\section{Frasch et al.}

642.

Martinez-Arias, A., N.E. Baker, and P.W. Ingham. 1988. Role of segment polarity genes in the definition and maintenance of cell states in the Drosophila embryo. Development 103: $157-170$.

Meinhardt, H. 1986. Hierarchical inductions of cell states: A model for segmentation in Drosophila. J. Cell Sci. (suppl.) 4! 357-381.

Nüsslein-Volhard, C. and E. Wieschaus. 1980. Mutations affecting segment number and polarity in Drosophila. Nature 287: 795-801.

Nüsslein-Volhard, C., H. Kluding, and G. Jurgens. 1985. Genes affecting the segmental subdivision of the Drosophila embryo. Cold Spring Harbor Symp. Quant. Biol. 50: 145-154.

Redemann, N., U. Gaul, and H. Jackle. 1988. Disruption of a putative Cys-zinc interaction eliminates the biological activity of the Kruppel finger protein. Nature 332: 90-92.

Rushlow, C., K. Harding, and M. Levine. 1987. Hierarchical interactions among pattern forming genes in Drosophila. In Developmental toxicology: Mechanisms and risks, Banbury Report 26 (ed. J. McLachlan et al.), pp. 93-108. Cold Spring Harbor Laboratory, Cold Spring Harbor, New York.

Sanger, F., S. Nicklen, and A.R. Coulson. 1977. DNA sequencing with chain-terminating inhibitors. Proc. Natl. Acad. Sci. 74: 5463-5467.

Wakimoto, B.T., F.R. Turner, and T.C. Kaufman. 1984. Defects in embryogenesis in mutants associated with the Antennapedia gene complex of Drosophila melanogaster. Dev. Biol. 102: $147-172$.

Yanisch-Perron, C., I. Vieira, and J. Messing. 1985. Improved M13 phage cloning vectors and host strains: nucleotide sequences of the M13 mpl8 and pUC19 vectors. Gene 33: 103-119. 


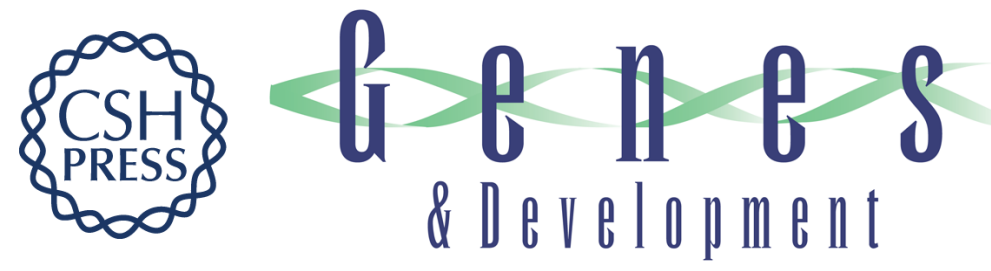

\section{Molecular analysis of even-skipped mutants in Drosophila development.}

M Frasch, R Warrior, J Tugwood, et al.

Genes Dev. 1988, 2:

Access the most recent version at doi:10.1101/gad.2.12b.1824

References This article cites 36 articles, 8 of which can be accessed free at:

http://genesdev.cshlp.org/content/2/12b/1824.full.html\#ref-list-1

License

Email Alerting

Service

Receive free email alerts when new articles cite this article - sign up in the box at the top right corner of the article or click here.

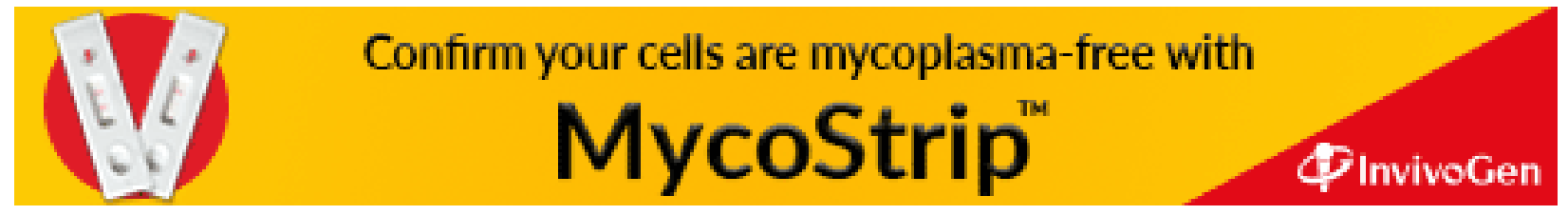

